\title{
Moroccan Bee Bread Improves Biochemical and Histological Changes of the Brain, Liver, and Kidneys Induced by Titanium Dioxide Nanoparticles
}

\author{
Meryem Bakour $\left(\mathbb{D},{ }^{1}\right.$ Nawal Hammas, ${ }^{2,3}$ Hassan Laaroussi $\left(\mathbb{D},{ }^{1}\right.$ Driss Ousaaid $\left(\mathbb{D},{ }^{1}\right.$ \\ Hinde EL Fatemi, ${ }^{2,3}$ Abderrazak Aboulghazi, ${ }^{1}$ Najoua Soulo, ${ }^{1}$ and Badiaa Lyoussi ${ }^{1}{ }^{1}$ \\ ${ }^{1}$ Laboratory of Natural Substances, Pharmacology, Environment, Modeling, Health and Quality of Life (SNAMOPEQ), Faculty of \\ Sciences Dhar El Mahraz, University Sidi Mohamed Ben Abdellah, Fez, Morocco \\ ${ }^{2}$ Laboratory of Biomedical and Translational Research, Faculty of Medicine and Pharmacy, University Sidi Mohamed Ben Abdellah, \\ $30000 \mathrm{Fez}$, Morocco \\ ${ }^{3}$ Department of Pathology, University Hospital Hassan II, 30000 Fez, Morocco
}

Correspondence should be addressed to Badiaa Lyoussi; lyoussi@gmail.com

Received 18 November 2020; Revised 1 June 2021; Accepted 15 June 2021; Published 24 June 2021

Academic Editor: Maqusood Ahamed

Copyright $\odot 2021$ Meryem Bakour et al. This is an open access article distributed under the Creative Commons Attribution License, which permits unrestricted use, distribution, and reproduction in any medium, provided the original work is properly cited.

Titanium dioxide nanoparticles $\left(\mathrm{TiO}_{2}\right)$ were used in various fields such as food industry, cosmetics, medicine, and agriculture. Despite the many advantages of nanotechnology, the adverse effects of nanoparticles are inevitable. The present study was conducted to evaluate the protective effect of bee bread on titanium dioxide $\left(\mathrm{TiO}_{2}\right)$ nanoparticle toxicity. Male rats were randomly divided into four groups: Group 1 received daily by gavage $(10 \mathrm{~mL} / \mathrm{kg} \mathrm{bw})$ of distilled water, Group 2 received bee bread ethanolic extract $\left(100 \mathrm{mg} / \mathrm{kg}\right.$ bw), Group 3 received $\mathrm{TiO}_{2}(100 \mathrm{mg} / \mathrm{kg}$ bw) and distilled water $(10 \mathrm{~mL} / \mathrm{kg}$ bw), and $\mathrm{Group} 4$ received $\mathrm{TiO}_{2}(100 \mathrm{mg} / \mathrm{kg} \mathrm{bw})$ and bee bread ethanolic extract $(100 \mathrm{mg} / \mathrm{kg} \mathrm{bw})$. All treatments were given daily by gavage during 30 days. At the end of the experiment period, blood samples were collected to analyze fasting blood glucose, lipid profile (TC, TG, LDL-C, HDL-C, and VLDL-C), liver enzymes (AST, ALT, and LDH), total protein, urea, albumin, creatinine, sodium, potassium, and chloride ions. In addition, histological examinations of the kidneys, liver, and brain were investigated. The results showed that the subacute administration of $\mathrm{TiO}_{2}$ alone $(100 \mathrm{mg} / \mathrm{kg} \mathrm{bw})$ had induced hyperglycemia $(309 \pm 5 \mathrm{mg} / \mathrm{dL})$ and elevation of hepatic enzyme levels, accompanied by a change in both lipid profile and renal biomarkers as well as induced congestion and dilatation in the hepatic central vein and congestion in kidney and brain tissues. However, the cotreatment with bee bread extract restored these biochemical parameters and attenuated the deleterious effects of titanium nanoparticles on brain, liver, and kidney functions which could be due to its rich content on functional molecules. The findings of this paper could make an important contribution to the field of using bee bread as a detoxifying agent against titanium dioxide nanoparticles and other xenobiotics.

\section{Introduction}

Titanium dioxide nanoparticles $\left(\mathrm{TiO}_{2} \mathrm{NPs}\right)$ are ultrafine particles ranging in size from 1 to 100 nanometers [1]. Due to the unique properties derived from their small sizes, $\mathrm{TiO}_{2} \mathrm{NPs}$ are widely used in paints, toothpastes, sunscreens, food colorants, medicines, pastry, and confectionery. Although $\mathrm{TiO}_{2} \mathrm{NPs}$ had many beneficial applications, it had also side effects. It is toxic when it is in powder form; it irri- tates the respiratory tract and could be carcinogenic and harmful to the cell structure [2]. Everyone has been exposed to nanosized $\mathrm{TiO}_{2}$ particles, because we inhale them with each breath and we consume them with every drink and food. However, several practical questions arise when dealing with the biological inertness. Thereby, the adverse effects of $\mathrm{TiO}_{2}$ nanoparticles have been shown in many studies, such as neuroinflammatory effect, brain injury [3], and pulmonary toxicity [4]. Titanium dioxide nanoparticles can damage spleen, 
which induces oxidative stress, apoptosis, liver injury, and heart damage.

The wide uses of nanoparticles in different aspects of life (food industry and medicine) increase chronic exposure to titanium particles. The toxicity of $\mathrm{TiO}_{2} \mathrm{NPs}$ can be induced by several mechanisms. These small particles could be inducing genetic toxicity through changing gene expression [5-7]. Additionally, it can be increasing the expression of cyp35a2 and dropping down the growth and fertility functions as toxicity endpoints size-dependent [8]. In the same context, the $\mathrm{TiO}_{2} \mathrm{NPs}$ had the ability to increase hepatic levels of interleukin 6 (IL6), nuclear factor kappa $\beta$, and tumor necrosis factor alpha $(\mathrm{TNF} \alpha)[9]$.

Another study revealed that the $\mathrm{TiO}_{2} \mathrm{NPs}$ can inhibit cell viability and neurite growth through the reduction of glutamine activity and NR1 expression, while it is able to stimulate the phosphate-activated glutaminase activity [10]. Moreover, $\mathrm{TiO}_{2} \mathrm{NPs}$ may produce oxidative stress via the production of reactive oxygen species (ROS) which counteract with DNA and generate 8 -OHG leading to errors and mutation in gene replication $[11,12]$.

The endpoints affected by $\mathrm{TiO}_{2} \mathrm{NPs}$ can be outlined in three mechanisms, the ROS production which induces electron-hole pairs, nanoparticle cell attachment which caused cell wall damage and lipid peroxidation, and the attachment of $\mathrm{TiO}_{2} \mathrm{NPs}$ to intracellular organelles and macromolecules inducing damage of cell membranes [13]. Therefore, we must find ways to reduce the impact of nanoparticles, especially those used in the food industry.

In the last years, there has been a growing interest in the use of natural products, which are widely cited in traditional medicine, yielding knowledge to derive bioactive molecules for drug discovery [14]. Bee products (honey, royal jelly, bee wax, propolis, bee pollen, and bee bread) are among the natural products that are known for their powerful healing properties such as antioxidant, nephroprotective, antiinflammatory, and antimicrobial effects [15-17].

Bee bread is a bee product obtained by an anaerobic fermentation process of a mixture of nutrients stored in the combs, constituted by the pollen collected by bees, honey, and digestive enzymes of bees [18]. The nutritional value of bee bread is higher than that of bee pollen, and it is more digestible. Bee bread contains all the essential amino acids, rich in vitamins such as vitamin $B$ and vitamin $K$; it is a good source of minerals like $\mathrm{K}, \mathrm{Mg}, \mathrm{Na}, \mathrm{Ca}, \mathrm{P}$, and $\mathrm{Mn}$. Bee bread also contains fatty acids, carbohydrates, and antioxidant compounds [18-20].

Numerous studies are aimed at evaluating the biological activities of bee bread, and they showed that it can be a source of many pharmacologically active molecules $[21,22]$. It was demonstrated that bee bread can act as a detoxifying agent against the toxicity of aluminum [17]; it improves glycemia in diabetics [23]. In vitro bee bread showed many biological properties such as antimicrobial, antioxidant, and antitumoral activities [24-26].

For all these reasons, this study was aimed at evaluating the protective effect of bee bread as a natural product against biochemical changes and tissue damages of the liver, kidneys, and brain caused by titanium dioxide nanoparticles in Wistar rats. Due to its efficiency and safety, ethanol was used as a conventional solvent from "nonnatural"/petroleum resources for the extraction of bioactive compounds from the bee bread sample [27-29].

\section{Material and Methods}

2.1. Titanium Nanoparticles. Titanium dioxide nanoparticles $\left(\mathrm{TiO}_{2}\right)$ were purchased from Sigma-Aldrich, Germany. The size of nanoparticles is $21 \mathrm{~nm}$. $\mathrm{TiO}_{2}$ dose $(100 \mathrm{mg} / \mathrm{Kg} \mathrm{bw})$ was chosen based on the findings of the toxicological studies conducted by Vasantharaja et al. [30] and Bu et al. [31].

2.2. Bee Bread Sample. Bee bread sample was obtained from a professional beekeeper, produced in Imouzzer Marmoucha $\left(33^{\circ} 28^{\prime} 12^{\prime \prime} \mathrm{N}\right.$ and $\left.4^{\circ} 17^{\prime} 24^{\prime \prime} \mathrm{W}\right)$ Morocco; the fresh product was stored at $-20^{\circ} \mathrm{C}$ until use. For the animal's experiment, bee bread was extracted using ethanol $(70 \%)$ by maceration for a week; the filtrate was concentrated by a rotary evaporator. Distilled water was added to obtain the concentration of $100 \mathrm{mg} / \mathrm{kg} \mathrm{bw})$. The dose was chosen according to Doganyigit et al. [32].

The full characterization of the bee bread sample used in this study was previously published, it is classified as multifloral, it contains $18 \pm 1 \mathrm{~g} / 100 \mathrm{~g}$ of total free sugars, $19.96 \pm$ $0.08 \mathrm{~g} / 100 \mathrm{~g}$ of proteins, $64.7 \pm 0.4 \%$ of polyunsaturated fatty acids, and $10.9 \pm 0.9 \mathrm{mg} / 100 \mathrm{~g}$ of tocopherols, minerals (Ca, $\mathrm{Fe}, \mathrm{K}, \mathrm{Mg}, \mathrm{Na}, \mathrm{Zn}, \mathrm{P}, \mathrm{Mn}$ ), and natural antioxidants (thirteen flavonol glycoside derivative, mainly methylherbacetrin, isorhamnetin, quercetin, and kaempferol derivatives); the major compound present was isorhamnetin-O-hexosyl-O-rutinoside [33].

2.3. Experimental Animals. Sixteen Wistar rats (body weight $150 \pm 10.20 \mathrm{~g}$ ) were used for in vivo experiment. The animals had free access to food and water. All animal procedures were conducted in accordance with the internationally accepted principles for laboratory animal use and care as found in the European Community guidelines (EEC Directive of 1986; 86/609/EEC). The protocol was approved by Sidi Mohamed Ben Abdellah University, Fez, Morocco (USMBA-SNAMOPEQ 2017-03), under the responsibility of the Laboratory of Natural Substances, Pharmacology, Environment, Modeling, Health and Quality of Life,

2.4. Experimental Design. Rats were randomly divided into four groups: Group 1 received $(10 \mathrm{~mL} / \mathrm{kg}$ bw) of distilled water, Group 2 received ethanolic extract of bee bread (100 $\mathrm{mg} / \mathrm{kg} \mathrm{bw})$, Group 3 received $\mathrm{TiO}_{2}(100 \mathrm{mg} / \mathrm{kg} \mathrm{bw})$ and $(10$ $\mathrm{mL} / \mathrm{kg}$ bw) of distilled water, and Group 4 received $\mathrm{TiO}_{2}$ $(100 \mathrm{mg} / \mathrm{kg} \mathrm{bw})$ and ethanolic extract of bee bread (100 $\mathrm{mg} / \mathrm{kg} \mathrm{bw}$ ). The interventions were provided daily by gavage for 30 days.

It is recommended for several biochemical analyses to use heparinized plasma, because firstly plasma constituents reflect better the pathologic state than serum [34] and secondly the volume of heparinized plasma is higher by $15 \%$ to $20 \%$ than serum obtained from the same volume of blood [35]. For that, blood samples were collected from each rat on day 30 by retro-orbital plexus using capillary tubes and 
heparin as anticoagulant; then, the blood samples were centrifuged at $4000 \mathrm{rpm}$ for $10 \mathrm{~min}$ at $4^{\circ} \mathrm{C}$, and the plasma samples obtained were conserved at $-20^{\circ} \mathrm{C}$ until analysis.

The kidneys, brain, and liver of each rat were removed and were immediately fixed in formalin solution (10\%).

2.5. Biochemical Methods. After 30 days of treatment, blood samples were collected for the analysis of alanine aminotransferase (ALT) (kit number 7D56-20, Alanine/NADH method); aspartate aminotransferase (AST) (kit number 7D81-20, Aspartate/NADH method); lactate dehydrogenase (LDH) (kit number 7D69-20, Lactate/NAD method); glucose (kit no 7D66-20, hexokinase method); creatinine (kit number 7D64-20, picric acid/NaOH method); urea (kit number 7D75-30, urease/NADH method); albumin (kit number 7D53-20, bromocresol Green method); total protein (kit number 7D73-20, biuret method); total cholesterol (TC) (kit number 7D62-20, cholesterol oxidase/POD method); triglycerides (TG) (kit number 7D74-20, lipase/GK/POD method); and high-density lipoprotein cholesterol (HDL-C) (kit number 7D67-20, homogeneous test method). Lowdensity lipoprotein cholesterol (LDL-C) was calculated according to the following formula:

$$
\mathrm{LDL}-\mathrm{C}=\mathrm{TC}-(\mathrm{HDL}-\mathrm{C}+\mathrm{TG} / 5)
$$

Very low-density lipoprotein (VLDL) was calculated using the following formula:

$$
\mathrm{VLDL}=\frac{\text { Triglycerides }}{5}
$$

All investigated parameters were measured using Architect c8000i biochemistry analyzer.

Plasma, chloride $\left(\mathrm{Cl}^{-}\right)$, sodium $\left(\mathrm{Na}^{+}\right)$, and potassium $\left(\mathrm{K}^{+}\right)$were analyzed using ion-selective potentiometry method (Architect c8000i biochemistry analyzer) (kit refs 1E49-01, LN9D28-02 and 1E48-20, respectively).

2.6. Histological Analysis. Histological analysis of the brain, liver, and kidney was performed using the method described by Bakour et al. [36]. The organs were fixed in the formalin solution (10\%) for $24 \mathrm{~h}$; then, tissue samples were dehydrated using ethanol with a series of increasing concentration; after, the organs were clarified in toluene and then embedded in paraffin. A microtome was used to cut fine sections (5-6 $\mathrm{mm}$ ) from paraffin blocks. Hematoxylin and eosin (H\&E) was used for staining the slides obtained for observation under an optical microscope (model BK 5000 Trino of the Realux brand).

2.7. Statistical Analysis. GraphPad Software (San Diego, CA, USA) was used for statistical analysis; data were represented as the mean \pm SEM. Statistical comparisons between groups were performed with one-way ANOVA followed by Bonferroni post hoc analysis. Throughout the analysis, $p<0.05$ was considered significant.

\section{Results}

3.1. Effect of Bee Bread on Enzymatic Liver Changes Induced by Titanium Dioxide Nanoparticles. The results of lactate dehydrogenase (LDH), alanine aminotransferase (ALT), and aspartate aminotransferase (AST) levels presented in Figure 1 revealed a significant elevation $(p<0.001)$ of these parameters in the group of rats that received $\mathrm{TiO}_{2}$ alone, compared with the control group. However, in the group who received the coadministration of $\mathrm{TiO}_{2}$ with the bee bread extract, the changes were lower compared to the group that received $\mathrm{TiO}_{2}$ alone, especially for ALT (Figure 1(b)).

\subsection{Effect of Bee Bread Extract on Lipid Profile Changes} Induced by Titanium Dioxide Nanoparticles. Figure 2 summarizes the results of lipid profile and shows a significant elevation of TC $\left({ }^{* * *} p<0.001\right)$, TG $\left({ }^{* * *} p<0.001\right)$, LDL $\left({ }^{*} p<0.05\right)$, and VLDL $\left({ }^{* *} p<0.01\right)$ and a decrease in HDL $\left({ }^{*} p<0.05\right)$ levels in the group of rats that received $\mathrm{TiO}_{2}$ nanoparticles only, while, in the group that received simultaneously $\mathrm{TiO}_{2}$ nanoparticles and bee bread extract, no significant changes were recorded in TC, LDL, and HDL as compared to the control group that received distilled water, while TG and VLDL levels were changed significantly (Figures 2(b) and 2(e)).

3.3. Effect of Bee Bread Extract on Plasma Glucose Change Induced by Titanium Dioxide Nanoparticles. Figure 3 presents the levels of glycemia in the treated groups; the results revealed a significant increase $\left({ }^{* * *} p<0.001\right)$ of the plasmatic glucose level in the group received $\mathrm{TiO}_{2}$ nanoparticles, compared to the control group that received distilled water. However, bee bread extract combined with $\mathrm{TiO}_{2}$ nanoparticles reduced significantly $\left({ }^{+++} p<0.001\right)$ the plasma glucose levels, in comparison to the group of rats that received $\mathrm{TiO}_{2}$ nanoparticles only.

3.4. Effect of Bee Bread on Plasmatic Changes of Creatinine, Urea, Total Protein, and Albumin Induced by Titanium Dioxide Nanoparticles. As shown in Figure 4, the subchronic administration of $\mathrm{TiO}_{2}$ caused a significant increase $\left({ }^{* * *} p<0.001\right)$ in the plasmatic urea level (Figure $\left.4(\mathrm{a})\right)$ and a significant decrease in total protein $\left({ }^{* * *} p<0.001\right)$ (Figure 4(c)) and albumin levels $\left({ }^{* * *} p<0.001\right)$ (Figure $4(\mathrm{~d})$ ), while no significant change was observed in creatinine plasmatic levels. The group of rats that received $\mathrm{TiO}_{2}$ nanoparticles combined with bee bread extract revealed significant protection $\left({ }^{+++} p<0.001\right)$ against the biochemical changes compared to the group received $\mathrm{TiO}_{2}$ nanoparticles only.

3.5. Effect of Bee Bread on Plasmatic Changes of Sodium, Potassium, and Chloride Induced by Titanium Dioxide Nanoparticles. Plasmatic concentrations of sodium, potassium, and chloride of the studied groups are summarized in Figure 5. The plasmatic levels of sodium, potassium, and chloride were significantly increased in the group received $\mathrm{TiO}_{2}$ nanoparticles only compared to the control group, while no significant increase was observed in the group coadministrated with bee bread extract combined and $\mathrm{TiO}_{2}$ nanoparticles. 


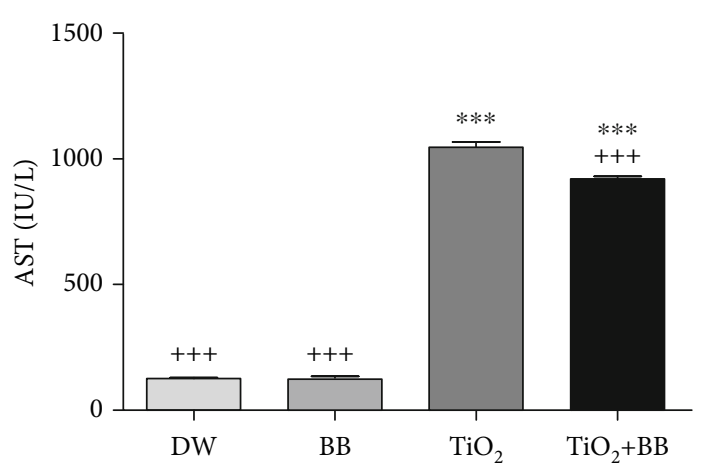

(a)

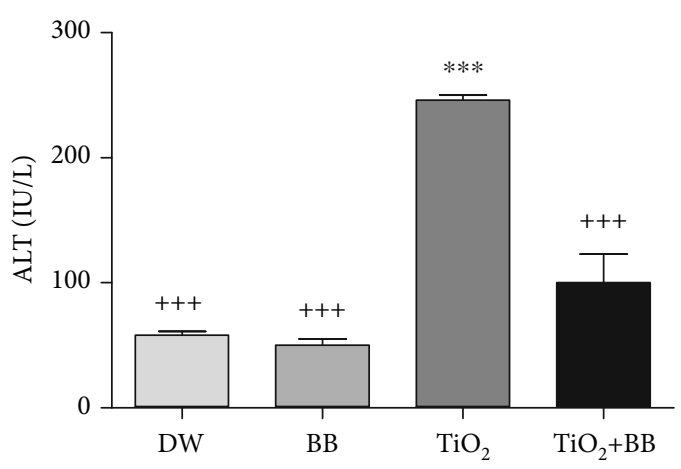

(b)

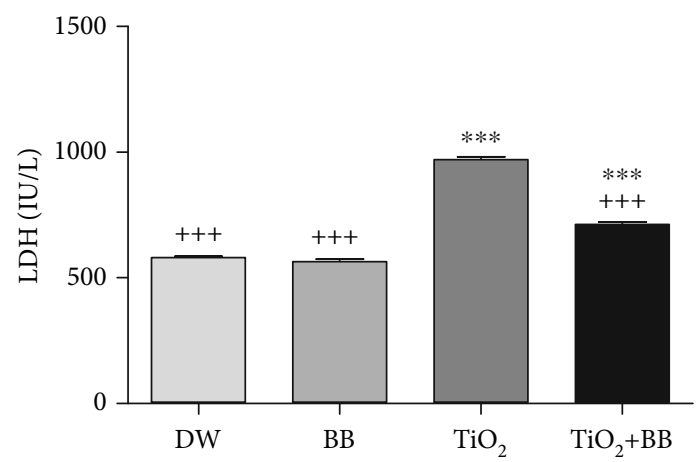

(c)

FIGURE 1: Effect of bee bread extract on liver enzymes changes induced by titanium dioxide nanoparticles. (a) AST plasma concentrations; (b) ALT plasma concentration; (c) $\mathrm{LDH}$ plasma concentration. DW: distilled water group; $\mathrm{BB}$ : bee bread group; $\mathrm{TiO}_{2}$ : titanium dioxide nanoparticle group; $\mathrm{TiO}_{2}+\mathrm{BB}$ : titanium dioxide nanoparticles+bee bread group. The symbol $(*)$ was used to present the statistical significance of the comparison between distilled water group (DW) and all groups using one-way ANOVA followed by Bonferroni post hoc analysis $\left({ }^{*} p<0.05 ;{ }^{* *} p<0.01 ;{ }^{* * *} p<0.001\right)$. The symbol $(+)$ was used to present the statistical significance of the comparison between titanium dioxide nanoparticle group $\left(\mathrm{TiO}_{2}\right)$ and all groups using one-way ANOVA followed by Bonferroni post hoc analysis $\left({ }^{+} p<0.05:{ }^{++} p<0.01 ;{ }^{+++} p<0.001\right)$. Data are the means of three replicates and presented as the mean \pm SEM.

3.6. Histological Analysis. The histological analysis of liver tissue (Figure 6) indicated that subacute administration of $\mathrm{TiO}_{2}$ nanoparticles alone induced congestion (Figure 6(c)) and dilatation in the central vein (Figure 6(d)). However, this dilation was less (Figure 6(e)) in rats cotreated with bee bread extract (Group 4).

The histological analysis of the kidney tissue (Figures 7) showed that $\mathrm{TiO}_{2}$ induced congestion when administered alone (Figure $7(\mathrm{c})$ ). However, the coadministration of bee bread extract with $\mathrm{TiO}_{2}$ for 30 days has reduced the intensity of congestion in renal tissue (Figure $7(\mathrm{e})$ ). In addition, as shown in (Figure $7(\mathrm{~d})$ ), particles of $\mathrm{TiO}_{2}$ appeared as agglomerates in the kidney tissue of untreated rats.

Concerning the histological analysis of brain tissue, the results presented in Figure 8 showed that titanium dioxide nanoparticles induced congestion in the brain tissue when administrated alone in rats (Figure 8(c)), while the coadministration of bee bread extract with $\mathrm{TiO}_{2}$ has protected the brain against this histopathological changes.

\section{Discussion}

$\mathrm{TiO}_{2}$ nanoparticles have been used in a wide variety of productive sectors such as food stuffs industry, cosmetics, and medicine. However, the safety of $\mathrm{TiO}_{2}$ nanoparticles expo- sure is still unclear [3]. A considerable amount of literature reports have been published on the toxic effect of $\mathrm{TiO}_{2}$ nanoparticles following exposure through different routes (oral, inhalation, and intravenous) [37-39]. Biodistribution studies have reported that titanium nanoparticles accumulate mainly in the liver and kidneys before their excretions, which requires the evaluation of their functional state when the toxicity of titanium has been investigated [39, 40]. In fact, the liver as a vital organ plays a key role in the mechanism of drug metabolism and xenobiotics detoxification; hence, it is highly recommended to evaluate its functional state when the toxic effects of titanium nanoparticles are explored [41]. After the hepatic metabolism of $\mathrm{TiO}_{2}$, the kidneys are the principal route of their excretion through glomerular filtration process, and $\mathrm{TiO}_{2}$ dioxide nanoparticles accumulate in the kidneys and subsequently induce renotoxicity. A previous study documented that approximately $20 \%$ of $\mathrm{TiO}_{2}$ nanoparticles persist chronically in the hematopoietic tissue of the kidney and do not reach the kidney tubules to be excreted in the urine [42]. Additionally, due to their small size, $\mathrm{TiO}_{2}$ nanoparticles cross the blood-brain barrier and accumulate in the brain, especially in the cortex and hippocampus and thus induce nervous cytotoxicity, inflammation, oxidative stress, and cell apoptosis [3, 43]. 


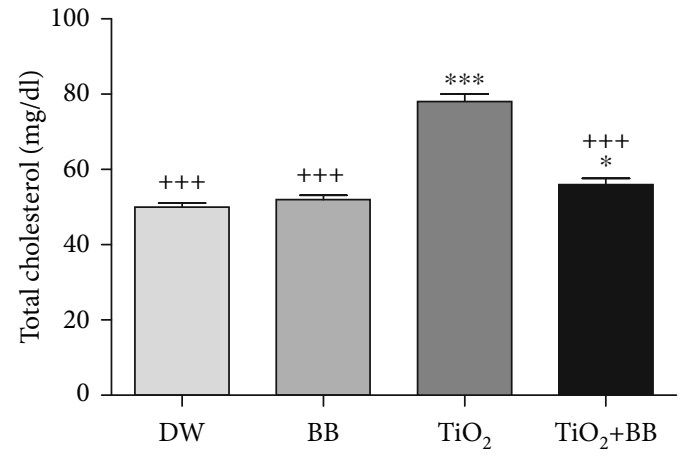

(a)

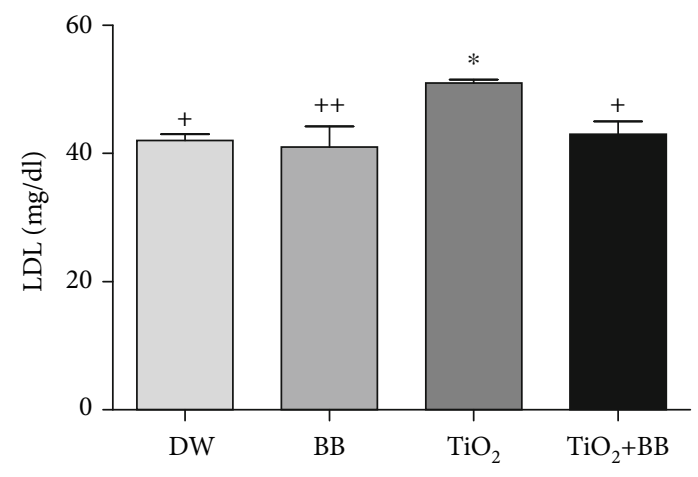

(c)

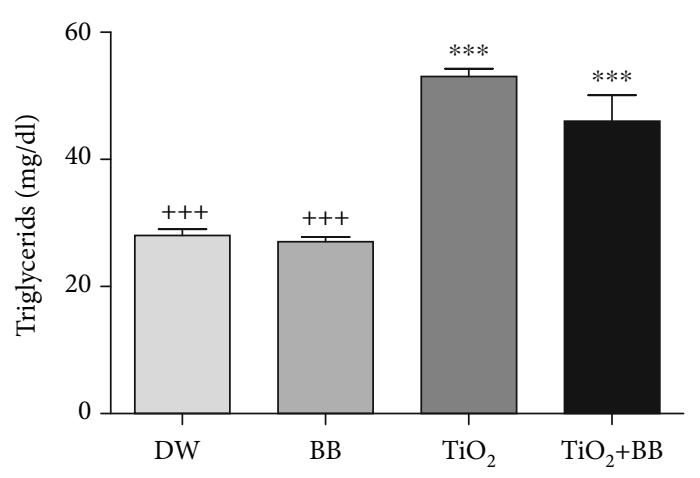

(b)

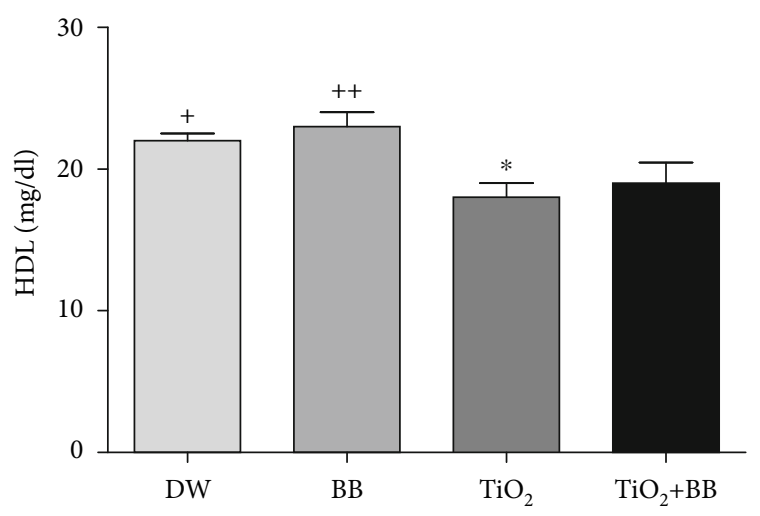

(d)

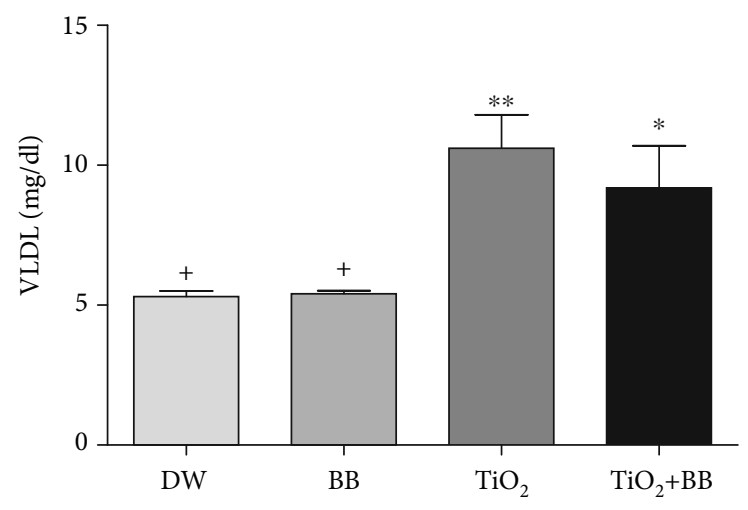

(e)

Figure 2: Effect of bee bread extract on lipid profile changes induced by titanium dioxide nanoparticles. (a) Total cholesterol concentration; (b) triglyceride concentration; (c) LDL concentration; (d) HDL concentration; (e) VLDL concentration. DW: distilled water group; BB: bee bread group; $\mathrm{TiO}_{2}$ : titanium dioxide nanoparticle group; $\mathrm{TiO}_{2}+\mathrm{BB}$ : titanium dioxide nanoparticles+bee bread group. The symbol $(*)$ was used to present the statistical significance of the comparison between distilled water group (DW) and all groups using one-way ANOVA followed by Bonferroni post hoc analysis $\left({ }^{*} p<0.05 ;{ }^{* *} p<0.01 ;{ }^{* * *} p<0.001\right)$. The symbol $(+)$ was used to present the statistical significance of the comparison between titanium dioxide nanoparticle group $\left(\mathrm{TiO}_{2}\right)$ and all groups using one-way ANOVA followed by Bonferroni post hoc analysis $\left({ }^{+} p<0.05:{ }^{++} p<0.01 ;{ }^{++} p<0.001\right)$. Data are the means of three replicates and presented as the mean \pm SEM.

In this work and in related references [44, 45], it was observed that nano- $\mathrm{TiO}_{2}$ administered orally induced a rise in serum transaminase activities (AST and ALT) as well as plasmatic LDH levels; the most likely explanation of these results is the liver injury due to toxin and, consequently, the leakage of cytoplasmic enzymes [46]. It was found that $\mathrm{TiO}_{2}$ nanomaterials induced hepatotoxicity through the over production of reactive oxygen species (ROS) [47]. Most importantly, the administration of bee bread extract alone did not change the plasma levels of these hepatic markers, which proves the safety of the $\mathrm{BB}$ extract at the tested dose $(100 \mathrm{mg} / \mathrm{kg} \mathrm{bw})$. The simultaneous administration of $\mathrm{BB}$ extract and $\mathrm{TiO}_{2}$ has reduced significantly the plasmatic ALT level and minimize the plasma elevation of LDH and AST levels, which illustrates its hepatoprotective effect. In fact, bee bread is a real source of bioactive molecules with a powerful hepatoprotective effect. Our previous work on the general 


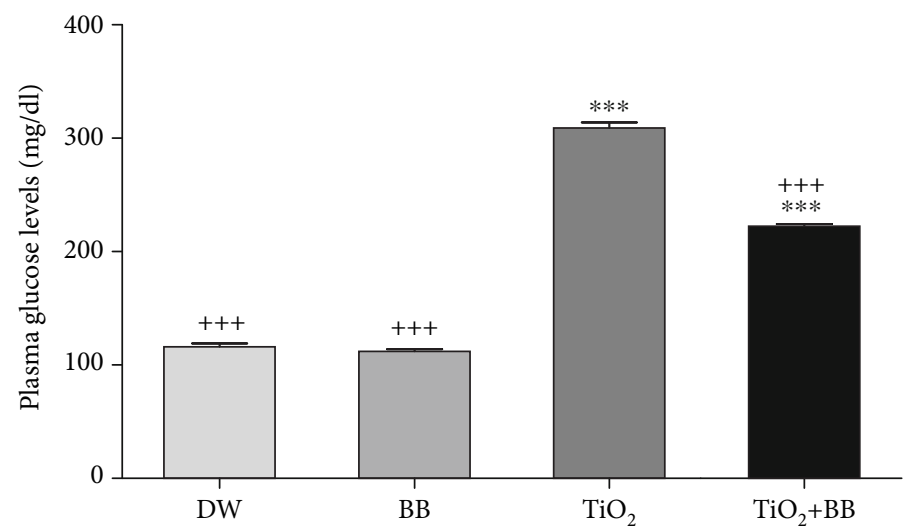

FIGURE 3: Effect of bee bread extract on plasma glucose changes induced by titanium dioxide nanoparticles. DW: distilled water group; BB: bee bread group; $\mathrm{TiO}_{2}$ : titanium dioxide nanoparticle group; $\mathrm{TiO}_{2}+\mathrm{BB}$ : titanium dioxide nanoparticles+bee bread group. The symbol $(*)$ was used to present the statistical significance of the comparison between distilled water group (DW) and all groups using one-way ANOVA followed by Bonferroni post hoc analysis $\left({ }^{*} p<0.05:{ }^{* *} p<0.01 ;{ }^{* * *} p<0.001\right)$. The symbol $(+)$ was used to present the statistical significance of the comparison between titanium dioxide nanoparticle group $\left(\mathrm{TiO}_{2}\right)$ and all groups using one-way ANOVA followed by Bonferroni post hoc analysis $\left({ }^{+} p<0.05:{ }^{++} p<0.01 ;{ }^{+++} p<0.001\right)$. Data are the means of three replicates and presented as the mean \pm SEM.

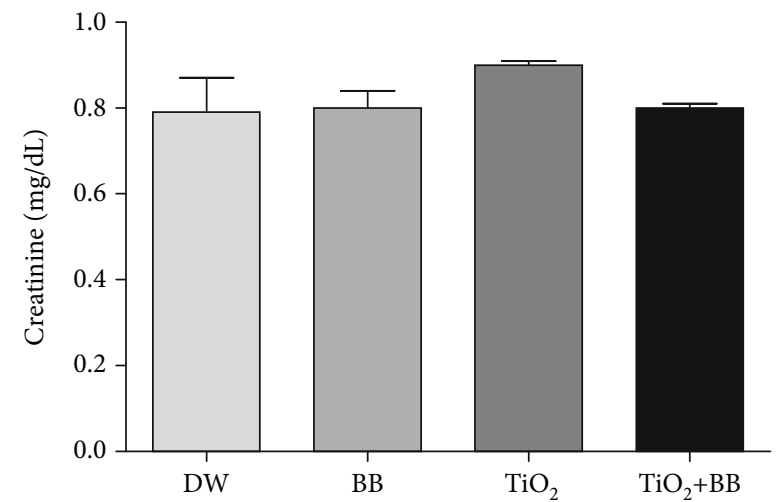

(a)

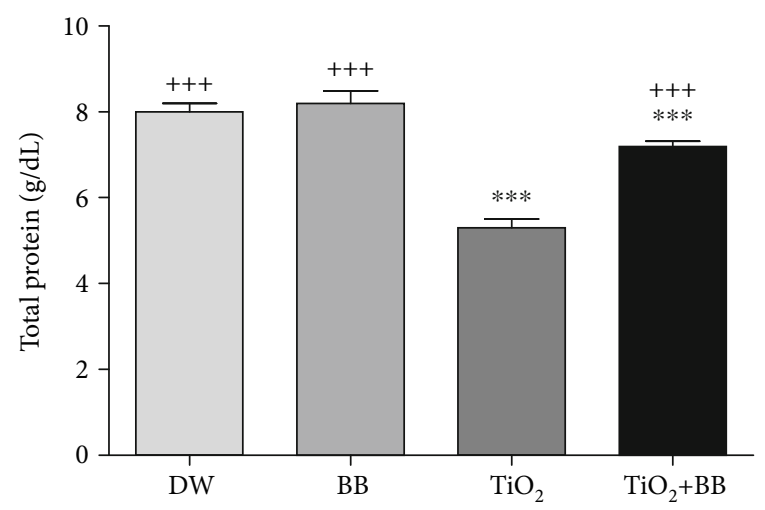

(c)

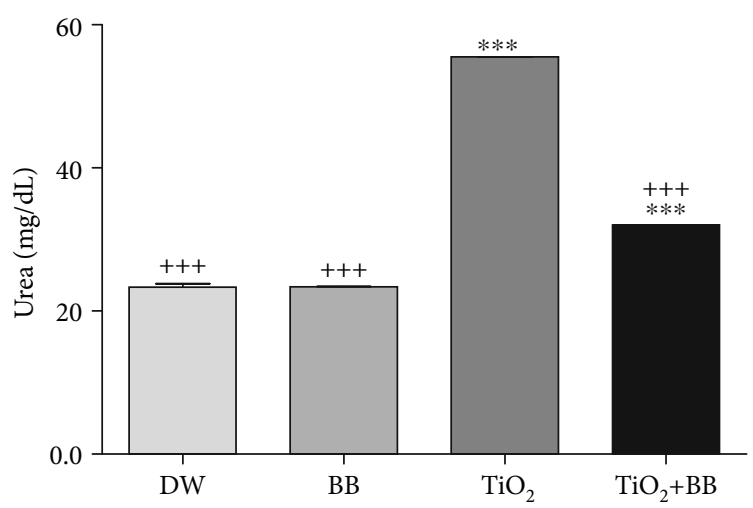

(b)

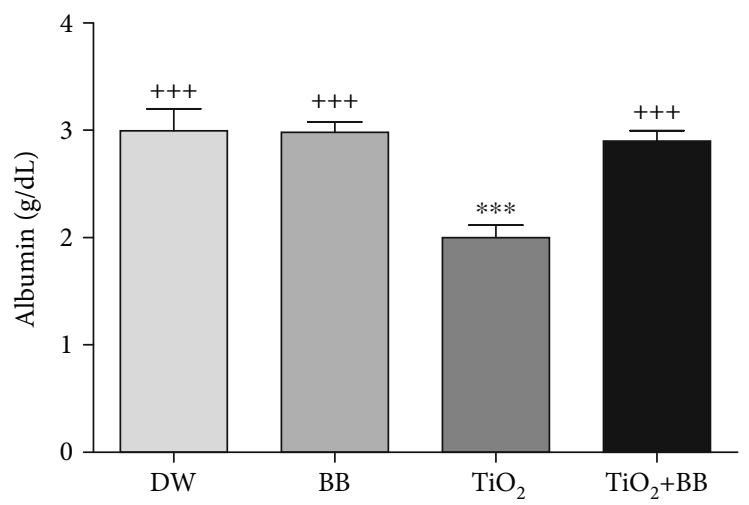

(d)

FIGURE 4: Effect of bee bread extract on plasmatic changes of (a) creatinine, (b) urea, (c) total protein, and (d) albumin induced by titanium dioxide nanoparticles. DW: distilled water group; $\mathrm{BB}$ : bee bread group; $\mathrm{TiO}_{2}$ : titanium dioxide nanoparticle group; $\mathrm{TiO}+\mathrm{BB}$ : titanium dioxide nanoparticles+bee bread group. The symbol $(*)$ was used to present the statistical significance of the comparison between distilled water group (DW) and all groups using one-way ANOVA followed by Bonferroni post hoc analysis $\left({ }^{*} p<0.05 ;{ }^{* *} p<0.01 ;{ }^{* * *} p<0.001\right)$. The symbol $(+)$ was used to present the statistical significance of the comparison between titanium dioxide nanoparticle group $\left(\mathrm{TiO}_{2}\right)$ and all groups using one-way ANOVA followed by Bonferroni post hoc analysis $\left({ }^{+} p<0.05 ;{ }^{++} p<0.01 ;{ }^{+++} p<0.001\right)$. Data are the means of three replicates and presented as the mean \pm SEM. 


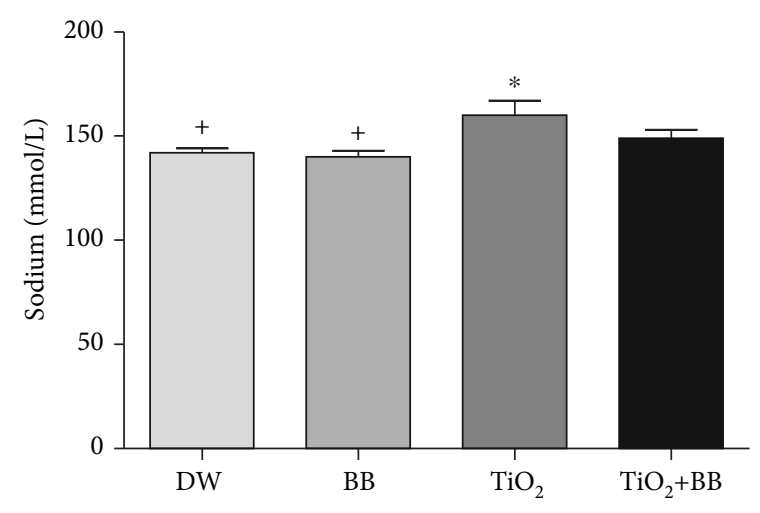

(a)

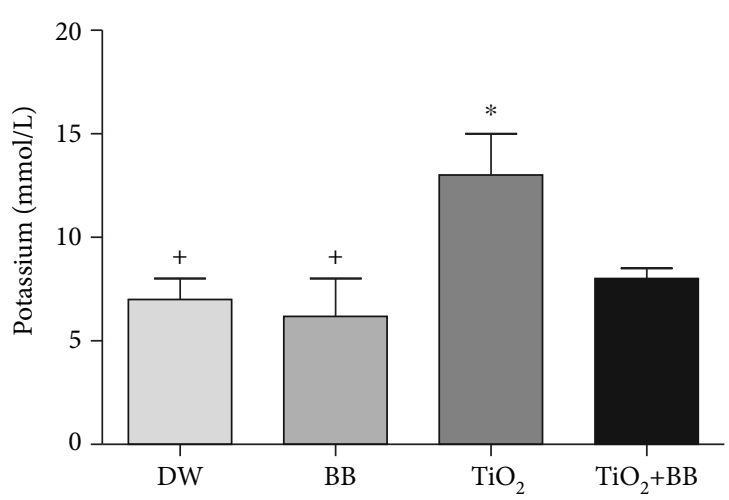

(b)

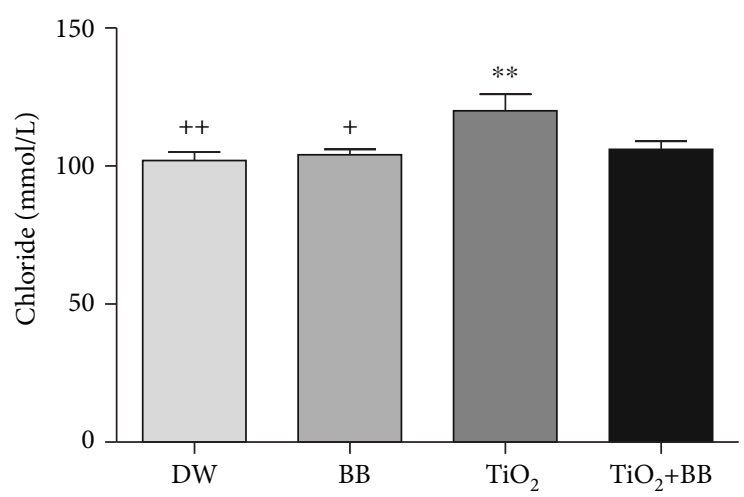

(c)

FIgURE 5: Effect of bee bread extract on plasmatic changes of (a) sodium, (b) potassium, and (c) chloride induced by titanium dioxide nanoparticles. DW: distilled water group; $\mathrm{BB}$ : bee bread group; $\mathrm{TiO}_{2}$ : titanium dioxide nanoparticle group; TiO $+\mathrm{BB}_{2}$ titanium dioxide nanoparticles+bee bread group. The symbol $(*)$ was used to present the statistical significance of the comparison between distilled water group (DW) and all groups using one-way ANOVA followed by Bonferroni post hoc analysis $\left({ }^{*} p<0.05 ;{ }^{* *} p<0.01 ;{ }^{* * *} p<0.001\right)$. The symbol (+) was used to present the statistical significance of the comparison between titanium dioxide nanoparticle group (TiO ${ }_{2}$ ) and all groups using one-way ANOVA followed by Bonferroni post hoc analysis $\left({ }^{+} p<0.05:{ }^{++} p<0.01 ;{ }^{+++} p<0.001\right)$. Data are the means of three replicates and presented as the mean \pm SEM.

characterization of the same bee bread sample used in the present study showed its rich composition in phytomolecules such as kaempferol-O-hexosyl-O-rutinosid, quercetin-O-hexosyl-O-hexoside, methylherbacetrin-O-dihexoside, isorhamnetin-O-hexosyl-O-rutinoside, quercetin-O-pentosylhexoside, quercetin-3-O-rutinoside, methylherbacetrin-3-Orutinoside, isorhamnetin-O-pentosyl-hexoside, isorhamnetinO-rhamnoside-hexoside, and isorhamnetin-3-O-rutinoside. Several studies have been reported the protective effect of quercetin and kaempferol against hepatotoxicity and liver diseases [48-50]. Therefore, the hepatoprotective effect of our sample extract most probably is due to the bioactivity of quercetin and kaempferol as well as the synergistic effect between its particular phytochemical components through different signaling pathways. In addition, the subacute administration of $\mathrm{TiO}_{2}$ nanoparticles increased significantly the fasting blood glucose levels (FBGL), which is in agreement with the data of Mao et al. [51]. Recent research has shown that ROS generated following the long term nano- $\mathrm{TiO}_{2}$ exposition was found to be the main mechanism associated with high FBGL; in turn, the persistently hyperglycemia triggers the overproduction of ROS and therefore decreases insulin biosynthesis and pro- motes insulin resistance $[52,53]$. The coadministration of $\mathrm{BB}$ extract for 30 days (Group 4) was able to reduce hyperglycemia, which is in agreement with the finding of Capcarova et al. [23]. Hypoglycemic activity of BB extract might be due to the interaction between its individual molecules, especially flavonoids vitamins C and B [54]. Indeed, Al-Ishaq et al. reported that flavonoid derivatives reduce hyperglycemia by modulating glucose transport in addition to their powerful antioxidant capacities [55].

Results of the present study reveal a change in lipid profile induced by $\mathrm{TiO}_{2}$ nanoparticles; the possible explanation of this result is that shown by Cui and coworkers, which have proven that titanium exposure can disrupt 785 hepatic genes and among those genes responsible for lipid metabolism [56]. In addition, changes in lipid profile following the subacute treatment with $\mathrm{TiO}_{2}$ nanoparticles referred to its inhibiting action on lipoprotein lipase activity (a main enzyme involved in the metabolism, transport, and tissue uptake of lipids) [57]. On the other hand, the simultaneous administration of $\mathrm{BB}$ extract and $\mathrm{TiO}_{2}$ nanomaterials modulates the lipid profile variations, which indicating that $\mathrm{BB}$ might reduce the risk and prevent the development of cardiovascular 


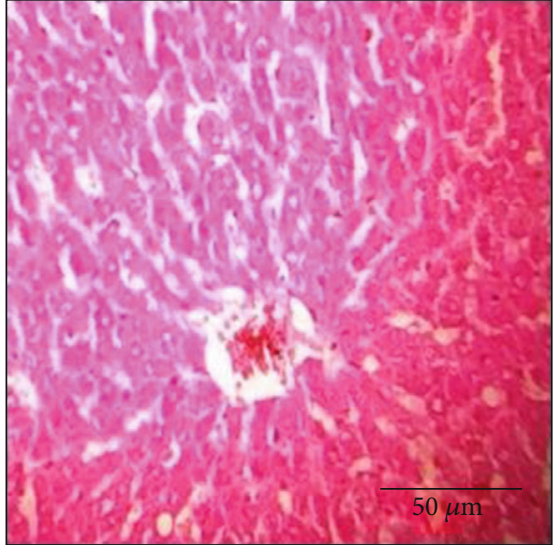

(a)

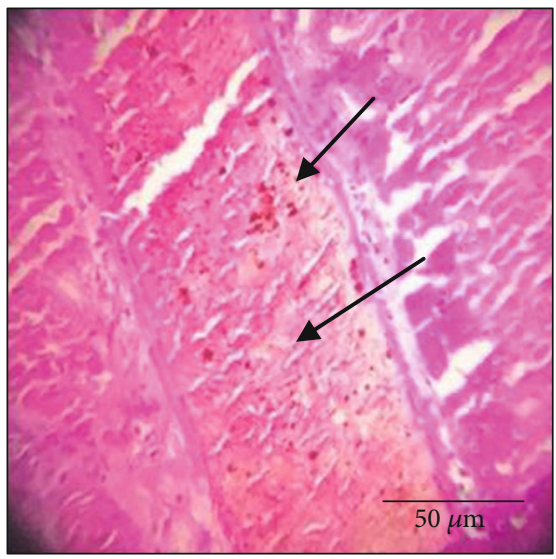

(c)

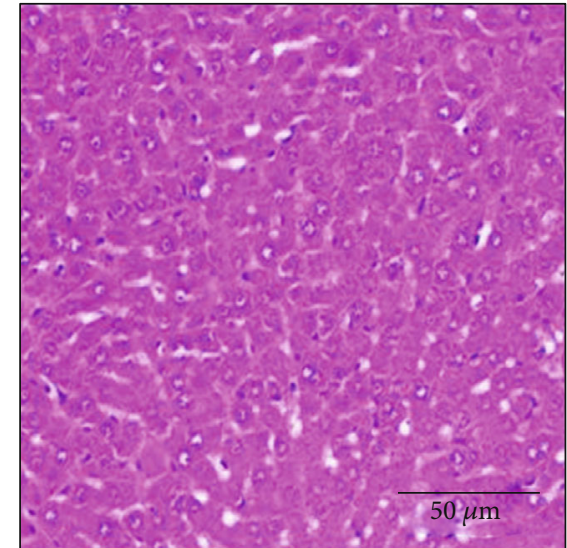

(b)

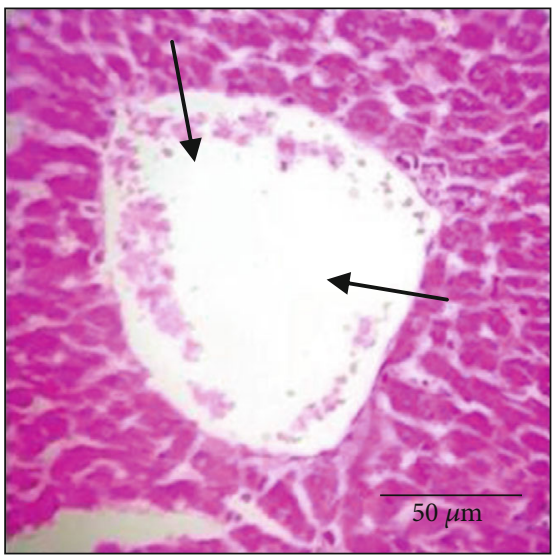

(d)

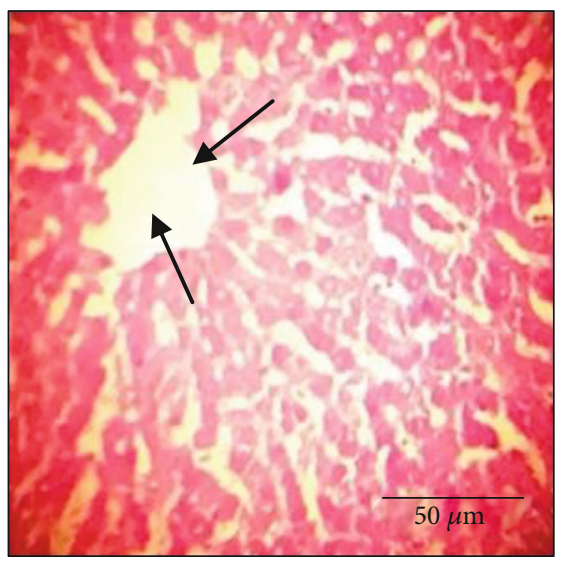

(e)

Figure 6: Histological evaluation of the liver. The arrows represent pathological changes in the tissue: (a) control group $-\times 100$; (b) BB group: normal tissue $-\times 100$; (c) $\mathrm{TiO}_{2}$ group: congestion $-\times 100$; (d) $\mathrm{TiO}_{2}$ group: dilatation in the central vein $-\times 100$; (e) $\mathrm{TiO}_{2}+\mathrm{BB}$ group: dilatation in the central vein $-\times 100$.

diseases. Similar results were reported by Othman et al. [58]. Growing reports suggest that lipid profile modulation is linked to the activity of caffeic and ferulic acids $[59,60]$, which are most probably present in the bee bread sample.

As shown in Figure 5, rats treated with $\mathrm{TiO}_{2}$ nanoparticles alone (group3) expressed significant elevation of creatinemia, plasmatic urea, and blood electrolytes levels $\left(\mathrm{Na}^{+}, \mathrm{K}^{+}\right.$, and $\left.\mathrm{Cl}^{-}\right)$accompanied by a decrease in total pro- tein and plasmatic albumin levels. These results go on hand with previous data $[30,44]$, whereas the concomitant treatment with $\mathrm{BB}$ extract showed noteworthy improvement of the major analyzed parameters. In fact, $\mathrm{BB}$ is a good source of polyphenols and flavonoids, antioxidants known to be effective against toxicity and renal damage induced by titanium nanomaterials; recently, it was suggested that polyphenols and flavonoids exert their 


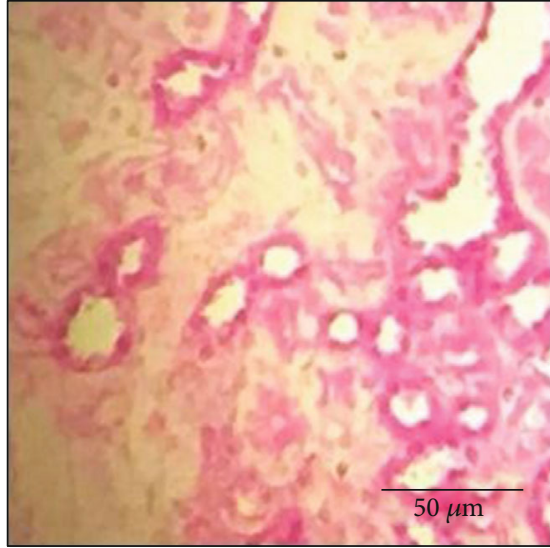

(a)

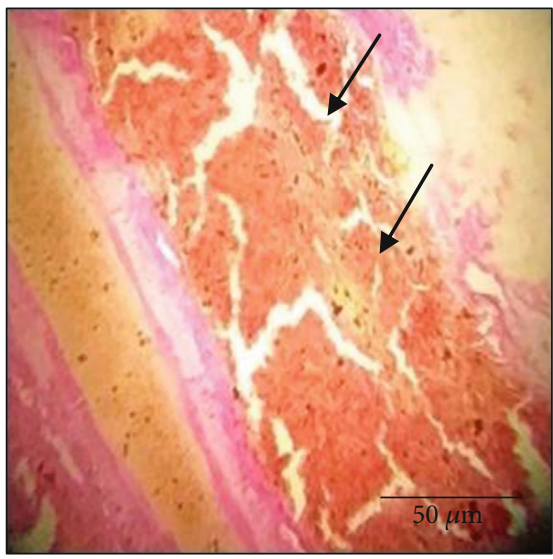

(c)

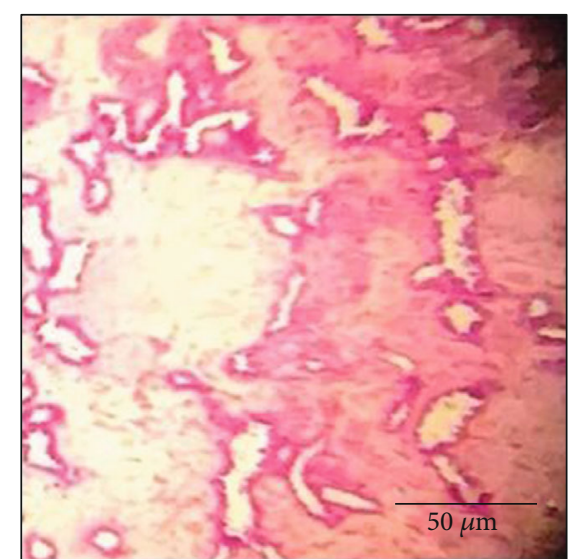

(b)

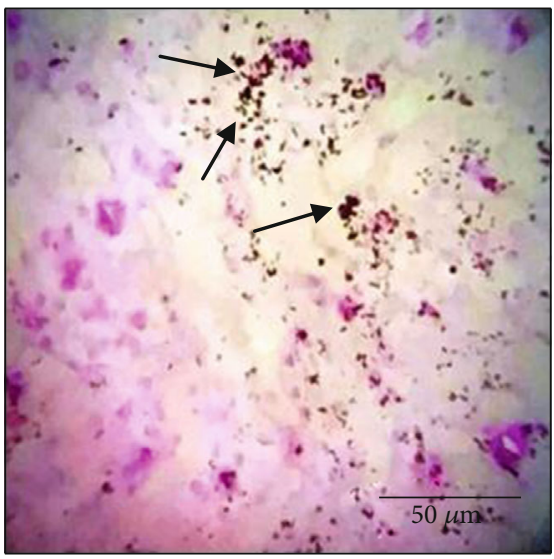

(d)

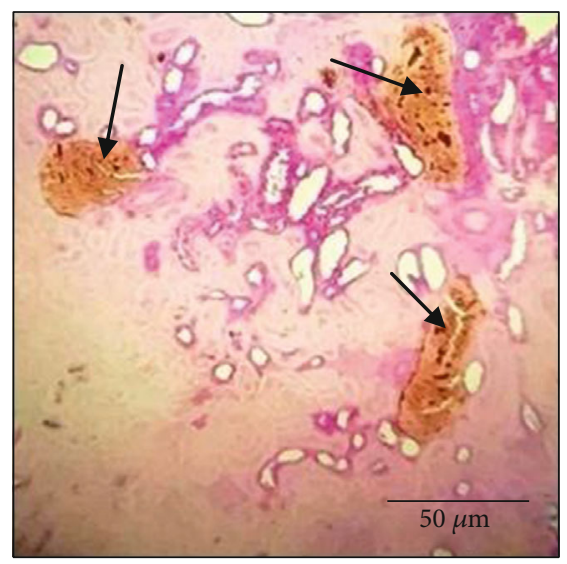

(e)

Figure 7: Histological evaluation of the kidney. The arrows represent pathological changes in tissue: (a) control group $-\times 100$; (b) BB group: normal tissue $-\times 100$; (c) $\mathrm{TiO}_{2}$ group: congestion $-\times 100$; (d) $\mathrm{TiO}_{2}$ group: particles of agglomerated $\mathrm{TiO}_{2}-\times 100$; $(\mathrm{d}) \mathrm{TiO}_{2}+\mathrm{BB}$ group: congestion $-\times 100$.

nephroprotective effects following their interaction with the cytoplasmic membrane of renal tubule cells [61].

After reaching the body, $\mathrm{TiO}_{2}$ nanoparticles attain tissues through bloodstream. Indeed, the histological examination of the kidney, brain, and liver tissues revealed that $\mathrm{TiO}_{2}$ nanoparticles cause serious pathological changes in these tissues. Based on previous studies [45, 62], oxidative stress has been suggested to be the main mechanism involved in $\mathrm{TiO}_{2}$ nano- particle toxicity which can lead to all these observed perturbations of serum biochemical parameters and histological damage of the liver and kidney tissue [63]. $\mathrm{TiO}_{2}$ nanoparticle biodistribution studies have shown that they tend to accumulate in the liver and kidneys and they are very difficult to eliminate because of their small size, which leads to damages in the liver and kidneys and causes also a disruption of the biochemical parameters [1]. 


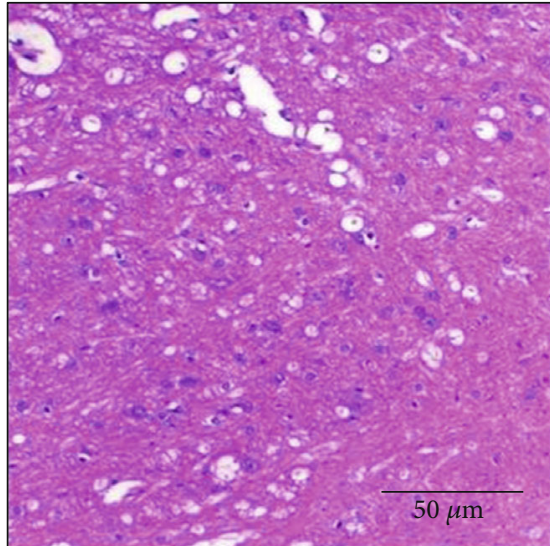

(a)

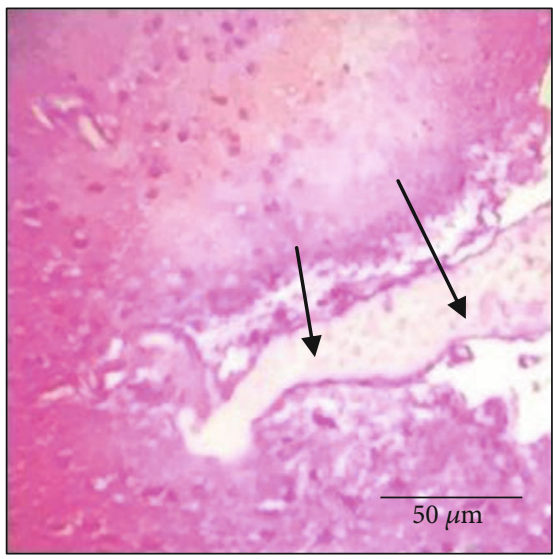

(c)

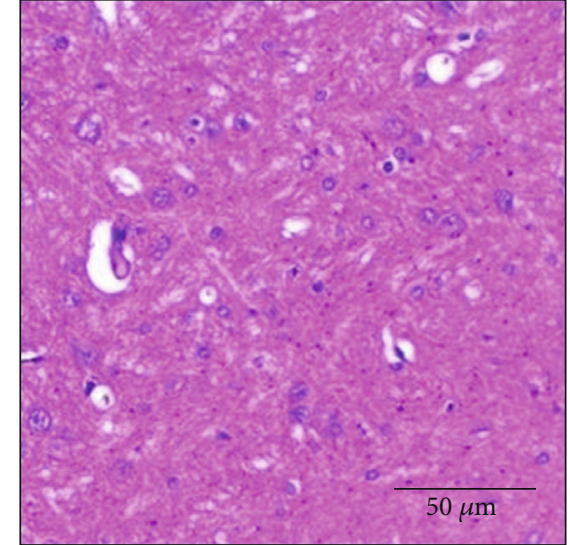

(b)

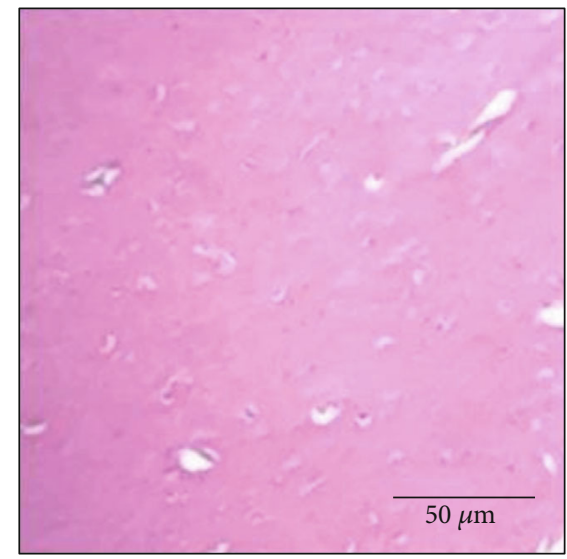

(d)

FIGURE 8: Histological evaluation of the brain. The arrows represent pathological changes in tissue: (a) control group $-\times 200$; (b) BB group: normal tissue $-\times 200$; (c) $\mathrm{TiO}_{2}$ group: congestion $-\times 100$; (d) $\mathrm{TiO}_{2}+\mathrm{BB}$ group: normal tissue $-\times 100$.

The issue of neurotoxicity of $\mathrm{TiO}_{2}$ nanoparticles has received considerable critical attention; recent studies have shown that $\mathrm{TiO}_{2}$ nanoparticles could induce disturbances of brain homeostasis, inflammation, neuron death, and brain injury $[63,64]$.

Several studies have been conducted to find protective tools against the toxicity of $\mathrm{TiO}_{2}$ nanoparticles $[45,62]$; to the authors' knowledge, no study has been performed on bee products. The empirical findings of this study showed that the coadministration of bee bread extract and $\mathrm{TiO}_{2}$ nanoparticles revealed a potent protective effect against the toxicity of titanium dioxide nanoparticles. The beneficial effects of bee bread could be attributed to its bioactive molecules and antioxidant compounds such as methylherbacetrin, quercetin, and kaempferol derivatives previously detected in the investigated sample $[25,33]$; these components are potentially able to protect many tissues against oxidative stress induced by $\mathrm{TiO}_{2}$ nanoparticles [65]. Numerous reports have established a link between the beneficial effect of bee bread and its composition in honey and bee pollen which could have a synergistic effect, boosting up its pharmacological activities and its therapeutic properties $[17,18]$.

\section{Conclusion}

One of the more significant findings to emerge from this study is that bee bread ethanolic extract has a very important protective effect against the majority of metabolic and histological disorders induced by the subacute intoxication of rats with $\mathrm{TiO}_{2}$ nanoparticles. Further studies are needed to know the exact protection mechanism and the active ingredient responsible for these beneficial effects.

\section{Data Availability}

The data used to support the findings of this study are included within the article.

\section{Conflicts of Interest}

The authors declare that they have no conflicts of interest.

\section{Acknowledgments}

The authors would like to thank Laboratory (SNAMOPEQ), Faculty of Sciences, Dhar El Mahraz, for providing the 
facilities to carry out the research work. The study was funded by the University Sidi Mohamed Ben Abdallah, P.O. Box 1796 Fez Atlas, Fez, Morocco (USMBA/PPSE/L08FSDM2018).

\section{References}

[1] A. Morgan, M. K. Galal, H. A. Ogaly, M. A. Ibrahim, R. M. Abd-Elsalam, and P. Noshy, "Tiron ameliorates oxidative stress and inflammation in titanium dioxide nanoparticles induced nephrotoxicity of male rats," Biomedicine \& Pharmacotherapy, vol. 93, pp. 779-787, 2017.

[2] T. Chen, J. Yan, and Y. Li, "Genotoxicity of titanium dioxide nanoparticles," Journal of Food and Drug Analysis, vol. 22, no. 1, pp. 95-104, 2014.

[3] M. Czajka, K. Sawicki, K. Sikorska, S. Popek, M. Kruszewski, and L. Kapka-Skrzypczak, "Toxicity of titanium dioxide nanoparticles in central nervous system," Toxicology In Vitro, vol. 29, no. 5, pp. 1042-1052, 2015.

[4] N. Hashizume, Y. Oshima, M. Nakai et al., "Categorization of nano-structured titanium dioxide according to physicochemical characteristics and pulmonary toxicity," Toxicology Reports, vol. 3, pp. 490-500, 2016.

[5] M. Geiser, B. Rothen-Rutishauser, N. Kapp et al., "Ultrafine particles cross cellular membranes by nonphagocytic mechanisms in lungs and in cultured cells," Environmental Health Perspectives, vol. 113, no. 11, pp. 1555-1560, 2005.

[6] L. Ma, Y. Ze, J. Liu et al., "Direct evidence for interaction between nano-anatase and superoxide dismutase from rat erythrocytes," Spectrochimica Acta. Part A, Molecular and Biomolecular Spectroscopy, vol. 73, no. 2, pp. 330-335, 2009.

[7] L. Ma, J. Zhao, J. Wang et al., "The acute liver injury in mice caused by nano-anatase TiO2," Nanoscale Research Letters, vol. 4, no. 11, pp. 1275-1285, 2009.

[8] J.-Y. Roh, Y.-K. Park, K. Park, and J. Choi, "Ecotoxicological investigation of $\mathrm{CeO}_{2}$ and $\mathrm{TiO}_{2}$ nanoparticles on the soil nematode Caenorhabditis elegans using gene expression, growth, fertility, and survival as endpoints," Environmental Toxicology and Pharmacology, vol. 29, no. 2, pp. 167-172, 2010.

[9] S. A. A. Azim, H. A. Darwish, M. Z. Rizk, S. A. Ali, and M. O. Kadry, "Amelioration of titanium dioxide nanoparticlesinduced liver injury in mice: possible role of some antioxidants," Experimental and Toxicologic Pathology, vol. 67, no. 4, pp. 305-314, 2015.

[10] F. Hong, L. Sheng, Y. Ze et al., "Suppression of neurite outgrowth of primary cultured hippocampal neurons is involved in impairment of glutamate metabolism and NMDA receptor function caused by nanoparticulate $\mathrm{TiO}_{2}$," Biomaterials, vol. 53, pp. 76-85, 2015.

[11] J. F. Reeves, S. J. Davies, N. J. F. Dodd, and A. N. Jha, "Hydroxyl radicals $(\bullet \mathrm{OH})$ are associated with titanium dioxide $\left(\mathrm{TiO}_{2}\right)$ nanoparticle- induced cytotoxicity and oxidative DNA damage in fish cells," Mutation Research/Fundamental and Molecular Mechanisms of Mutagenesis, vol. 640, no. 1-2, pp. 113-122, 2008.

[12] K. Hirakawa, M. Mori, M. Yoshida, S. Oikawa, and S. Kawanishi, "Photo-irradiated titanium dioxide catalyzes site specific DNA damage via generation of hydrogen peroxide," Free Radical Research, vol. 38, no. 5, pp. 439-447, 2004.
[13] J. Hou, L. Wang, C. Wang et al., "Toxicity and mechanisms of action of titanium dioxide nanoparticles in living organisms," Journal of Environmental Sciences, vol. 75, pp. 40-53, 2019.

[14] N. E. Thomford, D. A. Senthebane, A. Rowe et al., "Natural products for drug discovery in the 21st century: innovations for novel drug discovery," International Journal of Molecular Sciences, vol. 19, no. 6, p. 1578, 2018.

[15] N. El Menyiy, N. Al Waili, M. Bakour, H. Al-Waili, and B. Lyoussi, "Protective effect of propolis in proteinuria, crystaluria, nephrotoxicity and hepatotoxicity induced by ethylene glycol ingestion," Archives of Medical Research, vol. 47, no. 7, pp. 526-534, 2016.

[16] S. Touzani, N. al-Waili, N. el Menyiy et al., "Chemical analysis and antioxidant content of various propolis samples collected from different regions and their impact on antimicrobial activities," Asian Pacific Journal of Tropical Medicine, vol. 11, no. 7, pp. 436-442, 2018.

[17] M. Bakour, N. S. Al-Waili, N. El Menyiy et al., "Antioxidant activity and protective effect of bee bread (honey and pollen) in aluminum-induced anemia, elevation of inflammatory makers and hepato-renal toxicity," Journal of Food Science and Technology, vol. 54, no. 13, pp. 4205-4212, 2017.

[18] M. Kieliszek, K. Piwowarek, A. M. Kot, S. Błażejak, A. Chlebowska-Śmigiel, and I. Wolska, "Pollen and bee bread as new health-oriented products: a review," Trends in Food Science and Technology, vol. 71, pp. 170-180, 2018.

[19] G. DeGrandi-Hoffman, B. J. Eckholm, and M. H. Huang, "A comparison of bee bread made by Africanized and European honey bees (Apis mellifera) and its effects on hemolymph protein titers," Apidologie, vol. 44, no. 1, pp. 52-63, 2013.

[20] C. M. Zuluaga, J. C. Serratob, and M. C. Quicazana, "Chemical, Nutritional and bioactive characterization of Colombian beebread," Chemical Engineer, vol. 43, 2015.

[21] R. Markiewicz-Żukowska, S. K. Naliwajko, E. Bartosiuk et al., "Chemical composition and antioxidant activity of beebread, and its influence on the glioblastoma cell line (U87MG)," Journal of Apicultural Science, vol. 57, no. 2, pp. 147-157, 2013.

[22] A. Urcan, L. A. Mărghitaș, D. S. Dezmirean et al., "Chemical composition and biological activities of beebread-review," Bulletin of the university of agricultural sciences \& veterinary medicine Cluj-Napoca. Animal Science \& Biotechnologies, vol. 74, 2017.

[23] M. Capcarova, A. Kalafova, M. Schwarzova et al., "Consumption of bee bread influences glycaemia and development of diabetes in obese spontaneous diabetic rats," Biologia, vol. 75, no. 5, pp. 705-711, 2020.

[24] R. A. M. Akhir, M. F. A. Bakar, and S. B. Sanusi, "Antioxidant and antimicrobial activity of stingless bee bread and propolis extracts," AIP Conference Proceedings, vol. 1891, article 020090, 2017.

[25] F. Sobral, R. Calhelha, L. Barros et al., "Flavonoid composition and antitumor activity of bee bread collected in Northeast Portugal," Molecules, vol. 22, no. 2, p. 248, 2017.

[26] T. Nagai, T. Nagashima, N. Suzuki, and R. Inoue, “Antioxidant activity and angiotensin I-converting enzyme inhibition by enzymatic hydrolysates from bee bread," Zeitschrift für Naturforschung C, vol. 60, no. 1-2, pp. 133-138, 2005.

[27] S. Hemwimon, P. Pavasant, and A. Shotipruk, "Microwaveassisted extraction of antioxidative anthraquinones from roots of Morinda citrifolia," Separation and Purification Technology, vol. 54, no. 1, pp. 44-50, 2007. 
[28] Z. Guo, Q. Jin, G. Fan, Y. Duan, C. Qin, and M. Wen, "Microwave-assisted extraction of effective constituents from a Chinese herbal medicine Radix Puerariae," Analytica Chimica Acta, vol. 436, no. 1, pp. 41-47, 2001.

[29] P. Ferreira-Santos, E. Zanuso, Z. Genisheva, C. M. Rocha, and J. A. Teixeira, "Green and sustainable valorization of bioactive phenolic compounds from Pinus by-products," Molecules, vol. 25, no. 12, 2020.

[30] D. Vasantharaja, V. Ramalingam, and G. Aadinaath Reddy, "Oral toxic exposure of titanium dioxide nanoparticles on serum biochemical changes in adult male Wistar rats," Nanomedicine Journal, vol. 2, pp. 46-53, 2015.

[31] Q. Bu, G. Yan, P. Deng et al., "NMR-based metabonomic study of the sub-acute toxicity of titanium dioxide nanoparticles in rats after oral administration," Nanotechnology, vol. 21, no. 12, p. 125105, 2010.

[32] Z. Doganyigit, B. Yakan, and E. Kaymak, "The effects of feeding obese rats by bee bread on IL-6 expression in rat stomach," Proceedings, vol. 2, no. 25, p. 1570, 2018.

[33] M. Bakour, Â. Fernandes, L. Barros, M. Sokovic, I. C. F. R. Ferreira, and Badiaa lyoussi, "Bee bread as a functional product: chemical composition and bioactive properties," LWT, vol. 109, pp. 276-282, 2019.

[34] G. Banfi, K. Bauer, W. Brand et al., Use of Anticoagulants in Diagnostic Laboratory Investigations, World Health Organ, 2002.

[35] R. N. Carey, C. Jani, C. Johnson, J. Pearce, P. Hui-Ng, and E. Lacson, "Chemistry testing on plasma versus serum samples in dialysis patients: clinical and quality improvement implications," Clinical Journal of the American Society of Nephrology, vol. 11, no. 9, pp. 1675-1679, 2016.

[36] M. Bakour, N. Soulo, N. Hammas et al., "The antioxidant content and protective effect of argan oil and Syzygium aromaticum essential oil in hydrogen peroxide-induced biochemical and histological changes," International Journal of Molecular Sciences, vol. 19, no. 2, p. 610, 2018.

[37] J. Wang, G. Zhou, C. Chen et al., "Acute toxicity and biodistribution of different sized titanium dioxide particles in mice after oral administration," Toxicology Letters, vol. 168, no. 2, pp. 176-185, 2007.

[38] R. B. Baggs, J. Ferin, and G. Oberdorster, "Regression of pulmonary lesions produced by inhaled titanium dioxide in rats," Veterinary Pathology, vol. 34, no. 6, pp. 592-597, 1997.

[39] E. Fabian, R. Landsiedel, L. Ma-Hock, K. Wiench, W. Wohlleben, and B. van Ravenzwaay, "Tissue distribution and toxicity of intravenously administered titanium dioxide nanoparticles in rats," Archives of Toxicology, vol. 82, no. 3, pp. 151-157, 2008.

[40] K. Sugibayashi, H. Todo, and E. Kimura, "Safety evaluation of titanium dioxide nanoparticles by their absorption and elimination profiles," The Journal of Toxicological Sciences, vol. 33, no. 3, pp. 293-298, 2008.

[41] A. Y. Nasr, "Protective effect of aged garlic extract against the oxidative stress induced by cisplatin on blood cells parameters and hepatic antioxidant enzymes in rats," Toxicology Reports, vol. 1, pp. 682-691, 2014.

[42] T. M. Scown, R. van Aerle, B. D. Johnston et al., "High doses of intravenously administered titanium dioxide nanoparticles accumulate in the kidneys of rainbow trout but with no observable impairment of renal function," Toxicological Sciences, vol. 109, no. 2, pp. 372-380, 2009.
[43] T. Zeman, E.-W. Loh, D. Čierný, and O. Šerý, "Penetration, distribution and brain toxicity of titanium nanoparticles in rodents' body: a review," IET Nanobiotechnology, vol. 12, no. 6, pp. 695-700, 2018.

[44] K. M. A. Hassanein and Y. O. El-Amir, "Ameliorative effects of thymoquinone on titanium dioxide nanoparticles induced acute toxicity in rats," International Journal of Veterinary Science and Medicine, vol. 6, no. 1, pp. 16-21, 2018.

[45] A. Jafari, Y. Rasmi, M. Hajaghazadeh, and M. Karimipour, "Hepatoprotective effect of thymol against subchronic toxicity of titanium dioxide nanoparticles: biochemical and histological evidences," Environmental Toxicology and Pharmacology, vol. 58, pp. 29-36, 2018.

[46] M. Malakouti, A. Kataria, S. K. Ali, and S. Schenker, "Elevated liver enzymes in asymptomatic patients-what should I do?," Journal of Clinical and Translational Hepatology, vol. 5, no. 4, pp. 1-10, 2017.

[47] H. An, C. Ling, M. Xu et al., "Oxidative damage induced by nano-titanium dioxide in rats and mice: a systematic review and meta-analysis," Biological Trace Element Research, vol. 194, no. 1, pp. 184-202, 2020.

[48] S. Miltonprabu, M. Tomczyk, K. Skalicka-Woźniak et al., "Hepatoprotective effect of quercetin: from chemistry to medicine," Food and Chemical Toxicology, vol. 108, no. Part B, pp. 365-374, 2017.

[49] P. Yao, A. Nussler, L. Liu et al., "Quercetin protects human hepatocytes from ethanol-derived oxidative stress by inducing heme oxygenase-1 via the MAPK/Nrf2 pathways," Journal of Hepatology, vol. 47, no. 2, pp. 253-261, 2007.

[50] M. Wang, J. Sun, Z. Jiang, W. Xie, and X. Zhang, "Hepatoprotective effect of kaempferol against alcoholic liver injury in mice," The American Journal of Chinese Medicine, vol. 43, no. 2, pp. 241-254, 2015.

[51] Z. Mao, Y. Li, T. Dong et al., "Exposure to titanium dioxide nanoparticles during pregnancy changed maternal gut microbiota and increased blood glucose of rat," Nanoscale Research Letters, vol. 14, no. 1, pp. 26-26, 2019.

[52] S. Kawahito, H. Kitahata, and S. Oshita, "Problems associated with glucose toxicity: role of hyperglycemia-induced oxidative stress," World Journal of Gastroenterology, vol. 15, no. 33, pp. 4137-4142, 2009.

[53] J. W. Eriksson, “Metabolic stress in insulin's target cells leads to ROS accumulation - a hypothetical common pathway causing insulin resistance," FEBS Letters, vol. 581, no. 19, pp. 37343742, 2007.

[54] B. Demirci, O. Demir, T. Dost, and M. Birincioglu, "Protective effect of vitamin B5 (Dexpanthenol) on cardiovascular damage induced by streptozocin in rats," Bratislava Medical Journal, vol. 115, no. 4, pp. 190-196, 2014.

[55] R. K. Al-Ishaq, M. Abotaleb, P. Kubatka, K. Kajo, and D. Büsselberg, "Flavonoids and their anti-diabetic effects: cellular mechanisms and effects to improve blood sugar levels," Biomolecules, vol. 9, no. 9, p. 430, 2019.

[56] Y. Cui, H. Liu, Y. Ze et al., "Gene expression in liver injury caused by long-term exposure to titanium dioxide nanoparticles in mice," Toxicological Sciences, vol. 128, no. 1, pp. 171$185,2012$.

[57] H. Ahmadvand, M. Ani, and A. Moshtaghie, "Changes in biochemical parameters related to lipid metabolism following titanium treatment in Rat," Iranian Journal of Pharmacology and Therapeutics, vol. 9, 2010. 
[58] Z. A. Othman, W. S. Wan Ghazali, L. Noordin, N. A. Mohd. Yusof, and M. Mohamed, "Phenolic compounds and the anti-atherogenic effect of bee bread in high-fat diet-induced obese rats," Antioxidants, vol. 9, no. 1, p. 33, 2020.

[59] P. Stanely Mainzen Prince and K. Senthil Kumaran, "Preventive effects of caffeic acid on lipids, lipoproteins and glycoproteins in isoproterenol induced myocardial infarcted rats," Food Research International, vol. 45, no. 1, pp. 155-160, 2012.

[60] A. Bumrungpert, T. Pingeesakikul, N. Tirawanchai, S. Tuntipopipat, S. Lilitchan, and S. Komindr, "Effects of ferulic acid supplementation on lipid profiles, oxidative stress and inflammatory status in hypercholesterolemic subjects," The FASEB Journal, vol. 26, 2012.

[61] C. E. Escárcega-González, I. Reynoso-Andeola, F. JaramilloJuárez, H. Martínez-Ruvalcaba, and F. A. Posadas del Rio, "The ginkgo biloba extract reverses the renal effects of titanium dioxide nanoparticles in adult male rats," Biochemistry Research International, vol. 2016, Article ID 5781579, 9 pages, 2016.

[62] K. M. A. Hassanein and Y. O. El-Amir, "Protective effects of thymoquinone and avenanthramides on titanium dioxide nanoparticles induced toxicity in Sprague-Dawley rats," Pathology, Research and Practice, vol. 213, no. 1, pp. 13-22, 2017.

[63] M. Z. Rizk, S. A. Ali, M. A. Hamed, N. S. El-Rigal, H. F. Aly, and H. H. Salah, "Toxicity of titanium dioxide nanoparticles: effect of dose and time on biochemical disturbance, oxidative stress and genotoxicity in mice," Biomedicine \& Pharmacotherapy, vol. 90, pp. 466-472, 2017.

[64] L. Q. Shao and B. Song, "Chapter 5- Toxicity of Titanium Dioxide Nanoparticles on Brain," in Neurotoxicity of Nanomaterials and Nanomedicine, X. Jiang and H. Gao, Eds., Academic Press, 2017.

[65] S. M. Borghi, S. S. Mizokami, F. A. Pinho-Ribeiro et al., "The flavonoid quercetin inhibits titanium dioxide (TiO2)-induced chronic arthritis in mice," The Journal of Nutritional Biochemistry, vol. 53, pp. 81-95, 2018. 